\title{
Chronic myeloproliferative disorders: prognostic importance of new working classification
}

\author{
R Burkhardt, K Jaeger, G Kettner, G Helmer
}

\author{
Abteilung für \\ Knochenmarks- \\ diagnostik, \\ Medizinische Klinik \\ Innenstadt der \\ Universität, München, \\ West Germany \\ K Jaeger, R Burkhardt, \\ G Kettner, G Helmer \\ Arbeitsgruppe \\ Hämatomorphologie, \\ Institut für \\ Hämatologie der \\ Gesellschaft für \\ Strahlen- und \\ Umweltforschung \\ mbH (National Center \\ for Environmental \\ Sciences), München, \\ West Germany \\ R Burkhardt, G Kettner, \\ G Helmer \\ Correspondence to: \\ Professor R Burkhardt, \\ Flossmannstrasse 20, D-8000 \\ München 60, Federal \\ Republic of Germany. \\ Accepted for publication 6 \\ December 1989
}

\begin{abstract}
Variants of chronic myeloproliferative disorders (CMPD) were compared according to their clinical features and classified by bone marrow biopsy appearances. Subsequently, this classification was further evaluated using survival data and histological variables from iliac crest biopsy specimens of an additional 1391 patients, making a total of 2241 patients available for analysis of outcome. The patients were grouped again into three main classes: "typical"; "variant"; and "transformed". "Typical" comprised the "classic" groups. "Variant" included the less uniform myeloproliferative syndromes, distinguished also by more variable clinical features, a different prognosis, and a greater tendency to fibrotic and blastic transformation. "Transformed" defined the end stages of both "typical" and "variant" types. Ten subgroups were distinguished by different histology and prognosis. Particular prognostic importance was assigned to atypia and immaturity of haemopoiesis, predominance of individual haemopoietic cell line, number and anomalies of megakaryocytes and progressive fibrosis.

It is suggested that the proposed subclassification would be helpful for studies of epidemiology and therapeutic trials by allowing more homogeneous groups to be recognised.
\end{abstract}

The main groups of chronic myeloproliferative disorders (CMPD), polycythaemia vera, primary thrombocythaemia, and chronic granulocytic leukaemia $(\mathrm{CGL})^{1-3}$ are traditionally classified according to characteristic and at least temporarily constant clinical features, and by exclusion of borderline cases. In practice, however, even the "classic" groups show considerable prognostic inhomogeneity. ${ }^{45}$ For example, transformation to the fibrotic or blastic stages is hardly predictable, and several variants often have to be lumped together into ill defined groupsfor example, agnogenic myeloid metaplasia, ${ }^{6}$ acute myelosclerosis ${ }^{7}$ and blast crisis. ${ }^{8}$ In our previous study ${ }^{9}$ random biopsy specimens of all untreated patients with CMPD since the year 1960 (including those diagnosed as having "unclassified" CMPD) were analysed by comparing histological and clinical data. The purpose of the present analysis was to test the preliminary results by the use of a greater number of cases and survival data to identify the clinically relevant subgroups (see classification table 1 and revised classification in table 2).

\section{Methods}

Iliac crest biopsy specimens from 2241 patients with CMPD (850 untreated and 1391 previously treated) were evaluated by the methodology described in our previous paper, ${ }^{9}$ and the time of survival from biopsy until death or date of last contact were recorded. Observation of these patients started in 1960 and ended in 1985; the mean observation period was $45 \cdot 3$ months, with a minimum of one and a maximum of 303 months. Classification followed the previously defined model,${ }^{9}$ although the denominations were made more uniform (table 1).

Table 1 Preliminary histological classification of CMPD with principal sample characteristics

\begin{tabular}{|c|c|c|c|c|c|}
\hline Classes & Main groups & Subtypes & $\begin{array}{l}\text { Sample } \\
\text { size/n }\end{array}$ & $\begin{array}{l}\text { Mean age } \\
\text { (years) }\end{array}$ & $\begin{array}{l}\text { Median survival } \\
\text { time(months) }\end{array}$ \\
\hline I Typical & $\begin{array}{l}\text { Erythrocytic myelosis (Ery-M) } \\
\text { corresponding to polycythaemia vera } \\
\text { Megakaryocytic myelosis } \\
\text { corresponding to primary thrombocythaemia } \\
\text { Granulocytic myelosis (Gran-M) } \\
\text { corresponding to CGL }\end{array}$ & $\begin{array}{l}\text { EryGranMeg-M } \\
\text { Ery-M } \\
\text { Meg-M-d (Meg-diffuse) } \\
\text { Meg-M-c (Meg-clustered) } \\
\text { Gran-M-Meg + } \\
\text { Gran-M-Meg - }\end{array}$ & $\begin{array}{r}358 \\
21 \\
148 \\
75 \\
333 \\
66\end{array}$ & $\begin{array}{r}55 \cdot 9 \\
58 \cdot 1 \\
59 \cdot 8 \\
62 \cdot 1 \\
54 \cdot 8 \\
48 \cdot 2 \\
\end{array}$ & 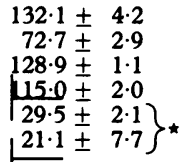 \\
\hline II Variant & $\begin{array}{l}\text { Erythrocytic myelosis variants corresponding to } \\
\text { borderline polycythaemia vera-primary thrombocythaemia } \\
\text { Megakaryocytic myelosis variants corresponding to } \\
\text { borderline primary thrombocythaemia or cytopenia } \\
\text { Granulocytic megakaryocytic myelosis corresponding to } \\
\text { borderline CGL-primary thrombocythaemia }\end{array}$ & $\begin{array}{l}\text { EryMeg-M } \\
\text { EryGran-M } \\
\text { Meg-M-i (Meg-immature) } \\
\text { Meg-M-p (Meg-pleomorphic) } \\
\text { GranMeg-M-d (Meg-diffuse) } \\
\text { GranMeg-M-c (Meg-clustered) }\end{array}$ & $\begin{array}{r}166 \\
80 \\
109 \\
18 \\
209 \\
228\end{array}$ & \begin{tabular}{r|}
$57 \cdot 9$ \\
$62 \cdot 9$ \\
$55 \cdot 0$ \\
$53 \cdot 8$ \\
$62 \cdot 0$ \\
$63 \cdot 3$ \\
\end{tabular} & $\begin{array}{r}94.8 \pm 13.0 \\
57.0 \pm 11.0 \\
12.3 \pm 3.5 \\
6.0 \pm 1.4 \\
64.6 \pm 4 \cdot 1 \\
49.6 \pm 5.5\end{array}$ \\
\hline III Transformed & $\begin{array}{l}\text { Osteomyelofibrosis variants corresponding to myeloid } \\
\text { metaplasia or cytopenia } \\
\text { Blastic osteomyelofibrosis variants similar to } \\
\text { malignant myelosclerosis } \\
\text { Blastic myelosis variants corresponding to } \\
\text { blastic crisis }\end{array}$ & $\begin{array}{l}\text { OMS (Osteomyelosclerosis) } \\
\text { MF (Myelofibrosis) } \\
\text { B-OMS } \\
\text { B-MF } \\
\text { B-M-mult (multilinear) } \\
\text { B-M-un (unilinear) }\end{array}$ & $\begin{array}{r}198 \\
48 \\
24 \\
64 \\
43 \\
53\end{array}$ & $\begin{array}{r}60 \cdot 8 \\
64 \cdot 8 \\
59 \cdot 6 \\
61 \cdot 2 \\
58 \cdot 7 \\
57 \cdot 0\end{array}$ & $\left.\begin{array}{r}\left.\begin{array}{r}30 \cdot 3 \pm \\
15 \cdot 0 \pm \\
6 \cdot 5 \pm \\
3 \cdot 5 \\
3 \cdot 8 \pm \\
10 \cdot 0 \pm \\
4 \cdot 6 \pm \\
4 \cdot 6 \\
1 \cdot 5\end{array}\right\}\end{array}\right\}$ \\
\hline
\end{tabular}

${ }^{\star}$ Horizontal lines between pairs of data indicate that the difference between the respective means is significant at the $0=1 \%$ level 


\begin{tabular}{|c|c|c|}
\hline \multicolumn{3}{|r|}{ Abbreviations } \\
\hline B-M & $=$ & blastic myelosis \\
\hline $\mathrm{B}-\mathrm{M}-\mathrm{V}$ & $=$ & blastic myelosis variants: \\
\hline B-M-un & $=$ & blastic myelosis unilinear \\
\hline B-M-mult & $=$ & blastic myelosis multilinear \\
\hline $\mathrm{B}-\mathrm{MF}$ & $=$ & blastic myelofibrosis \\
\hline B-OMS & $=$ & blastic osteomyelosclerosis \\
\hline CGL & $=$ & chronic granulocytic leukaemia \\
\hline CMPD & $=$ & chronic myeloproliferative disorder \\
\hline Ery-M & $=$ & erythrocytic myelosis \\
\hline Ery-M-V & $=$ & erythrocytic myelosis variants: \\
\hline EryGranMeg-M & $=$ & erythro-granulo-megakaryocytic myelosis \\
\hline EryGran-M & $=$ & erythro-granulocytic myelosis \\
\hline EryMeg-M & $=$ & erythro-megakaryocytic myelosis \\
\hline Gran-M & $=$ & granulocytic myelosis \\
\hline Gran-M-V & $=$ & granulocytic myelosis variants: \\
\hline Gran-M-Meg- & $=$ & granulocytic myelosis poor in megakaryocytes \\
\hline Gran-M-Meg + & $=$ & granulocytic myelosis rich in megakaryocytosis \\
\hline GranMeg-M & $=$ & granulo-megakaryocytic myelosis \\
\hline GranMeg-M-V & $=$ & granulo-megakaryocytic myelosis variants: \\
\hline GranMeg-M-d & $=$ & granulo-megakaryocytic myelosis with diffuse megakaryocytosis \\
\hline GranMeg-M-c & $=$ & granulo-megakaryocytic myelosis with clustered megakaryocytosis \\
\hline Meg-M & $=$ & megakaryocytic myelosis \\
\hline Meg-M-V & $=$ & megakaryocytic myelosis variants: \\
\hline Meg-M-d & $=$ & megakaryocytic myelosis with diffuse megakaryocytosis \\
\hline $\mathrm{Meg}-\mathrm{M}-\mathrm{c}$ & $=$ & megakaryocytic myelosis with clustered megakaryocytosis \\
\hline $\mathrm{Meg}-\mathrm{M}-\mathrm{i}$ & $=$ & megakaryocytic myelosis with immature megakaryocytosis \\
\hline Meg-M-p & $=$ & megakaryocytic myelosis with pleomorphic megakaryocytosis \\
\hline
\end{tabular}

Class I was primarily defined by the accepted criteria (chromosomal analyses were available only in a few cases), and subdivided according to the histological features mentioned above.

Classes II and III were defined by histology alone, with the exception of the PV variants. Pure blastic variants were included only when antecedent CMPD was confirmed; blastic variants combined with typical myelofibrosis or osteomyelosclerosis were generally registered as B-MF or B-OMS, most tracing back to original CMPD. Myelofibrosis and osteomyelosclerosis groups were defined only by those cases in which fibrotic or osteosclerotic changes had already obscured the typical CMPD characteristic. The diagnosis as CMPD was then deduced either from remaining foci of (predominantly megakaryocytic) myeloproliferation or the case history. Cases of CMPD with only minor fibrotic or osteosclerotic changes, including reticular sclerosis, were assigned to their original groups.
Definitions of the various conditions, together with correlations of histological changes with clinical and haematological data, have been given previously. ${ }^{510}$ The former concerned the different forms of megakaryocytes (normal, dwarf, giant, immature, and pleomorphic), the proliferation, maturity, and predominance of haemopoietic cell lines, and the conditions of reticular sclerosis, myelofibrosis, and osteomyelosclerosis, as well as the correlations of histological changes with clinical and haematological data. The reliability of the histological data had already been assured by at least two observers and the use of at least five differently stained slides.

The survival periods were correlated with the patients' age and sex, the histological subtypes, and the fibrotic and non-fibrotic changes in the biopsy specimen. The data were analysed using BMPD statistical packages. ${ }^{11}$ Differences between groups were tested for significance using the methods of Breslow ${ }^{12}$ and Mantel-Cox. ${ }^{13}$

Table 2 Revised histological classification of CMPD: clinical appearance, age, fibrosis and survival

\begin{tabular}{|c|c|c|c|c|c|}
\hline Classification & & $\begin{array}{l}\text { Clinical appearance } \\
\text { corresponding with }\end{array}$ & $\begin{array}{l}\text { Mean age } \\
\text { (years) }\end{array}$ & $\begin{array}{l}\text { Collagenous } \\
\text { fibrosis }(\%)\end{array}$ & $\begin{array}{l}\text { Median } \\
\text { survival } \\
\text { (months) }\end{array}$ \\
\hline $\begin{array}{l}\text { Class I: typical }(\mathrm{n}=1001) \\
\text { Group } 1 \text { Erythrocytic myelosis (Ery-M; EryGranMeg-M) } \\
2 \text { Megakaryocytic myelosis }(\mathbf{M e g}-\mathbf{M}-\mathrm{d} ; \mathbf{M e g}-\mathbf{M}-\mathrm{c}) \\
3 \text { Granulocytic myelosis (Gran-M-Meg }+;-\mathbf{M e g}-)\end{array}$ & $\begin{array}{l}17 \% \\
10 \% \\
18 \%\end{array}$ & $\begin{array}{l}\text { Polycythaemia vera, typical } \\
\text { Primary thrombocythaemia, typical } \\
\text { CGL, typical }\end{array}$ & $\begin{array}{l}56 \cdot 0 \\
60 \cdot 5 \\
54 \cdot 8 / 48 \cdot 2\end{array}$ & $\begin{array}{l}5 \% \\
13 \% \\
19 \% / 9 \%\end{array}$ & $\begin{array}{l}128 \cdot 8 \\
124 \cdot 2 \\
29 \cdot 5 / 21 \cdot 1\end{array}$ \\
\hline $\begin{array}{l}\text { Class II Variant }(\mathrm{n}=683) \\
\text { Group } \\
4 \text { Erythrocytic-megakaryocytic myelosis (EryMeg-M) } \\
5 \text { Erythrocytic-granulocytic myelosis (EryGran-M) } \\
6 \text { Granulocytic-megakaryocytic myelosis } \\
\text { (GranMeg-M-d; GranMeg-M-c) }\end{array}$ & $\begin{array}{r}7 \% \\
3 \% \\
20 \%\end{array}$ & $\begin{array}{l}\text { Polycythaemia vera, primary } \\
\text { thrombocythaemia, borderline } \\
\text { Polycythaemia vera/CGL, borderline } \\
\text { CGL/primary thrombocythaemia, } \\
\text { borderline }\end{array}$ & $\begin{array}{l}57 \cdot 9 \\
62 \cdot 4 \\
62 \cdot 6\end{array}$ & $\begin{array}{l}37 \% \\
30 \% \\
46 \%\end{array}$ & $\begin{array}{l}94 \cdot 8 \\
57 \cdot 0 \\
56 \cdot 8\end{array}$ \\
\hline $\begin{array}{l}\text { Class III Transformed }(\mathrm{n}=557) \\
\text { Group } 7 \text { Osteomyelosclerosis (OMS) } \\
8 \text { Myelofibrosis (MF) } \\
9 \text { Blastic myelosis, multinear (B-M-mult; B-OMS; } \\
\text { B-MF) } \\
10 \text { Blastic myelosis, unilinear (B-M-un) }\end{array}$ & $\begin{array}{r}9 \% \\
2 \% \\
12 \% \\
2 \% \\
100 \%\end{array}$ & $\begin{array}{l}\text { Myeloid metaplasia or cytopenia } \\
\text { Myeloid metaplasia or cytopenia } \\
\text { Blastic crisis or malignant } \\
\text { myelosclerosis } \\
\text { Blastic crisis } \\
2 \cdot 241 \text { cases }\end{array}$ & $\begin{array}{l}60 \cdot 8 \\
64 \cdot 8 \\
57 \cdot 5 \\
57 \cdot 0\end{array}$ & $\begin{array}{r}100 \% \\
100 \% \\
45 \% \\
17 \%\end{array}$ & $\begin{array}{r}30 \cdot 3 \\
15 \cdot 0 \\
8 \cdot 8 \\
4 \cdot 6\end{array}$ \\
\hline
\end{tabular}


Figure 1a Erythrocytic myelosis (EryGranMegM) corresponding to polycythaemia vera: typical trilinear

proliferation with incipient cluster formation of

megakaryocytes and slight reticular sclerosis.

(Gomori's silver impregnation.)

$1 b$ Granulocytic myelosis (Gran-M-Meg + corresponding to CGL: typical granulocytic proliferation with strong increase in dwarf megakaryocytes; incipient transformation into Meg$M-i$ ? (Gallamin blue-

Giemsa stain.)

1c Megakaryocytic myelosis (Meg-M-c) corresponding to primary thrombocythaemia: typical proliferation of giant megakaryocytes among otherwise normal haemopoiesis. (Gallamin blue-Giemsa stain.

Id Granulo-megakaryocytic myelosis (GranMeg$M-c)$; granulocytic proliferation together with accumulations of giant megakaryocytes in large clusters. (Gallamin blueGiemsa stain.)
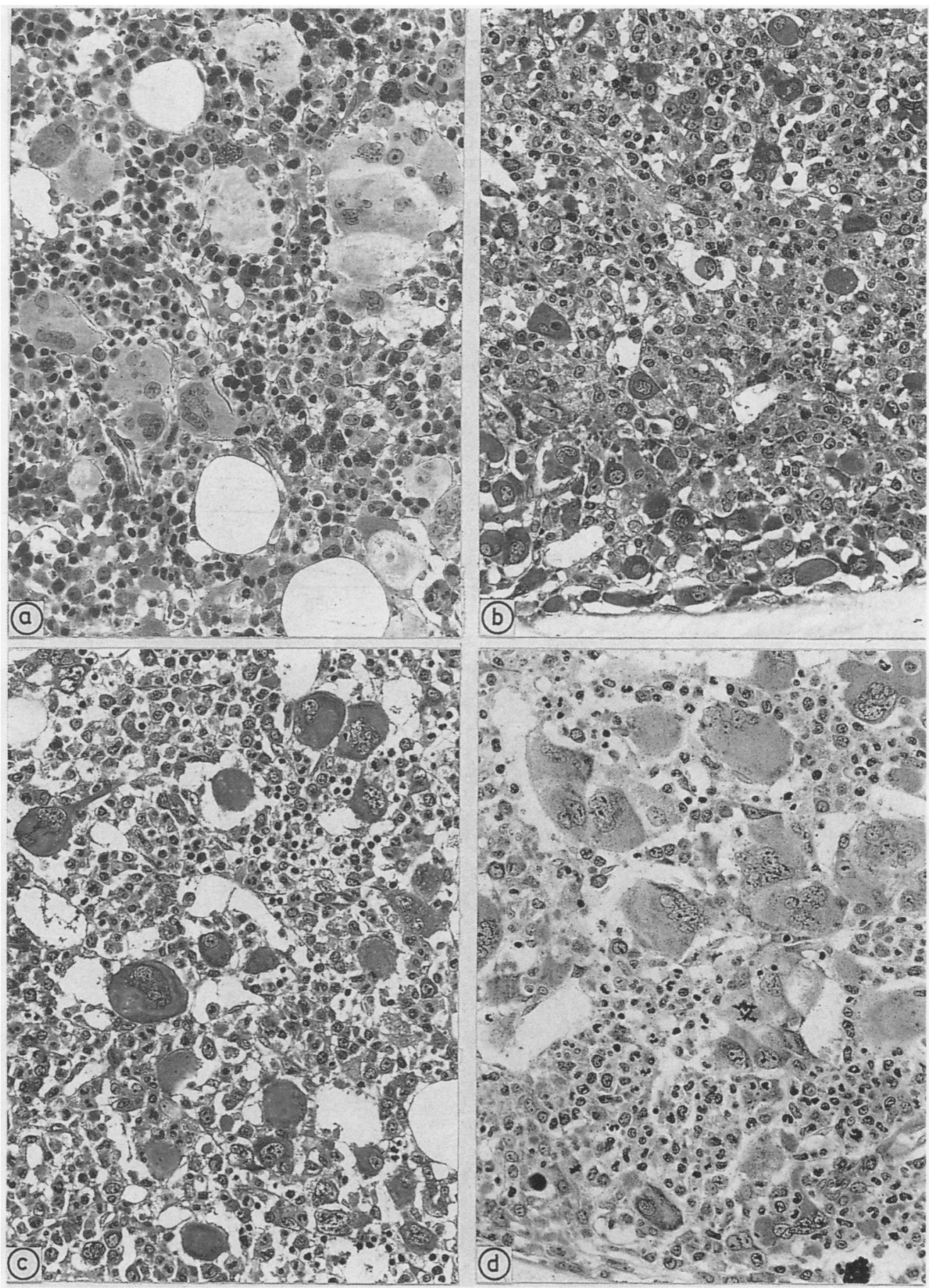

\section{Results}

Sixty three per cent of the patients had died; thirty seven per cent were known to be still alive. The longest median survival was $132 \cdot 1$ months (EryGranMeg-M = polycythaemia vera), the shortest 3.8 months (B-MF). The median survivals of patients untreated at the time of biopsy did not differ significantly from those of patients who had already received specific treatment. This applied to all types and subtypes. Moreover, comparative histological evaluation showed no reasons for a separate analysis of treated and untreated patients. The overall ratio between male and female patients was $1.03: 1$; significant predominance of one sex (female) was found only in mature and immature megakaryocytic myelosis (Meg-M and Meg-M-i).
OVERALL SURVEY (table 1)

The number of patients was higher and the mean age lower in the typical class than in the variant and transformed classes ( $\mathbf{n}=$ 1001:810:430 patients; mean ages = $56 \cdot 1: 60 \cdot 4: 60 \cdot 6$ years). These figures seem to support the hypothesis that the classes I to III represent sequential stages of CMPD.

Within each class, differences in the median survivals of the main groups were as follows (the symbol > denotes longer than): I: Ery(GranMeg)-M > Gran-M; Meg-M > Gran-M; II: Ery-M-V > Meg-M-i; GranM-V > Meg-M-i; III: OMS > B-OMS; OMS > B-M.

Significantly different median survival times were also detected between corresponding pairs of subtypes (different pairs marked 
Figure 2 Life table: survivals for three megakaryocytic subtypes of CMPD; $A=($ Meg- $M$ respectively primary thrombocythaemia) $; B=$ (GranMeg-M); $C=$ (Meg-M-i)

Figure $3 a$

Megakaryocytic immature myelosis (Meg-M-i); large sheets of mostly

immature megakaryocytes. ( Gallamin blue-Giemsa stain.)

$3 b$ Myelofibrosis; small groups of immature, partially necrotic

megakaryocytes amid fibrotic obliteration of the marrow space. (Gomori's silver impregnation.) $3 c$ Osteomyelosclerosis (OMS); irregular strands of primitive bone, produced by osteoblasts, enclosing islets of haemopoietic bone marrow with numerous giant and necrotic megakaryocytes. (Gallamin blue-Giemsa stain.)

$3 d$ Blastic multilinear myelosis (B-M-mult); irregular proliferation of blastic elements of all cell lines, predominantly

pleomorphic

megakaryoblasts and cytes, and collagenous fibrosis. (Gallamin blueGiemsa stain.
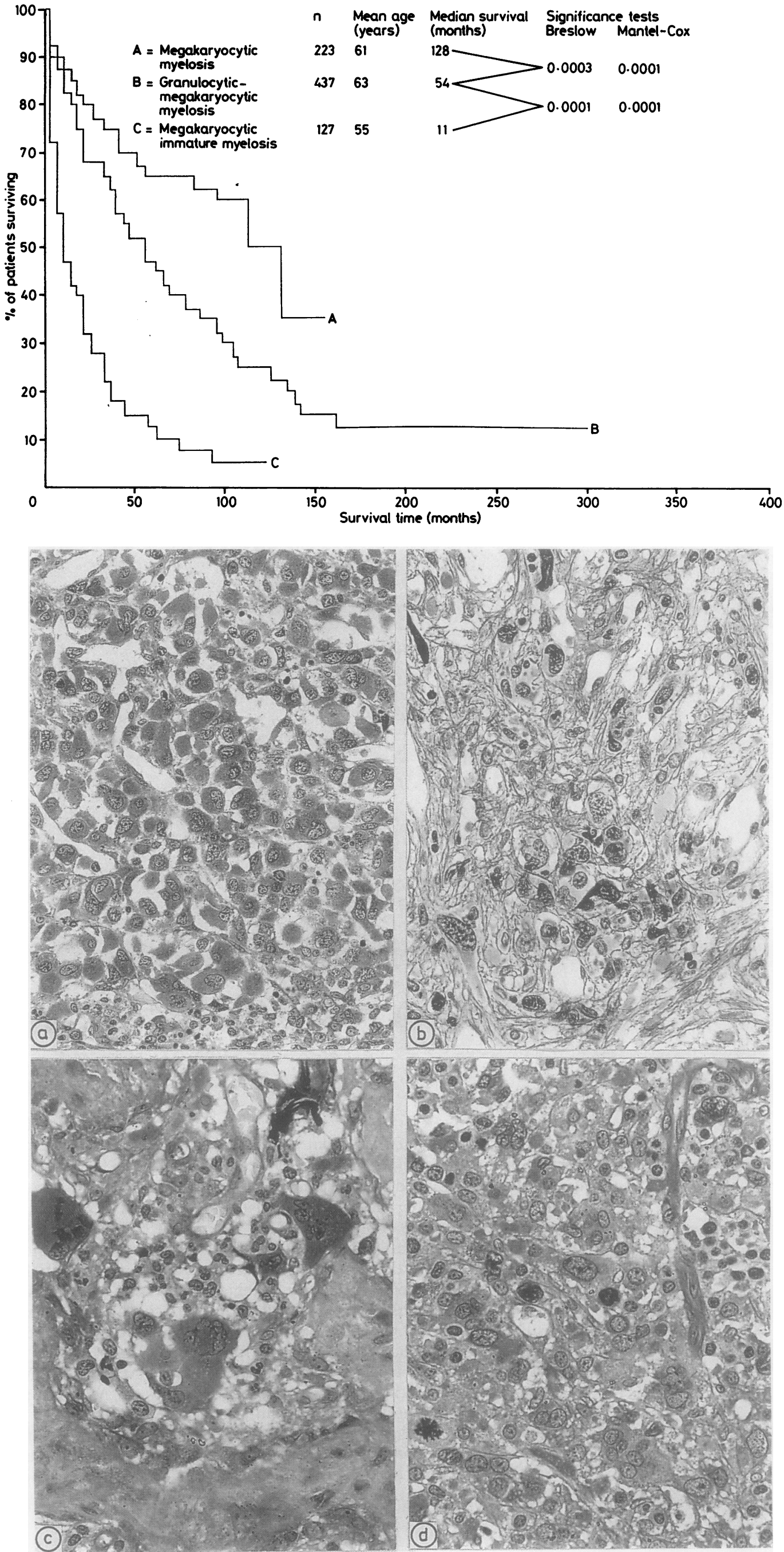
Figure 4 Life table: survivals for four transformed subtypes of $C M P D ; A=$ osteomyelosclerosis $(O M S) ; B=$ myelofibrosis (MF);C= blastic multilinear myelosis (B-M-mult) $; D=$ blastic unilinear myelosis ( $B-M$ un) grouped together with blastic osteomyelosclerosis (B-OMS), and blastic myelofibrosis ( $B-M F)$.

Figure 5 Life table: correlation of fibrotic changes and survival of 1955 patients with CMPD including all subtypes except $O M S, B-O M S$, and $B-M F)$.

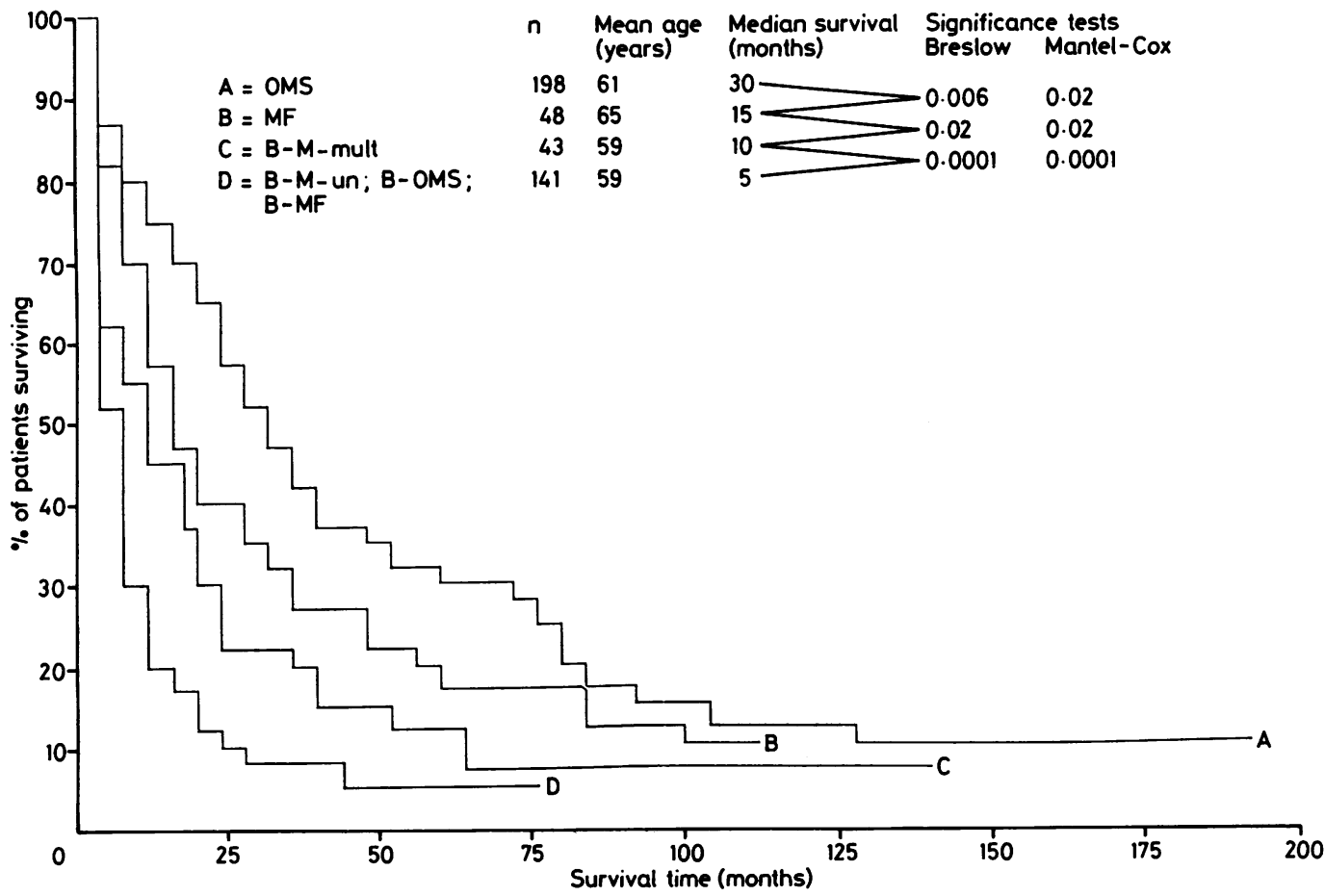

by horizontal lines): thus Gran-M-Meg $+>$ Gran-M-Meg - , in spite of the lower mean age of the latter group; and EryMeg-M > EryGran-M. In the latter case the second group was older, but not enough to explain the different life spans; OMS $>$ MF (once again age alone could not explain the difference in life expectancy); B-M-mult $>$ B$M$-un (while the mean ages of these groups were almost the same).

COMPARISON OF SURVIVAL TIMES OF SUBTYPES (ACCORDING TO PREDOMINANT CELL LINES)

Erythrocytic predominance

Median survival times of EryGranMeg-M were equal to that of typical polycythaemia vera. Moreover, of the variant subtypes of polycythaemia vera, the survival times for
EryMeg-M (fig 1a), differed from those of EryGran-M; $p=0.0001$ (Breslow and Mantel-Cox tests). Pure Ery-M comes closer to the variant subtypes in this respect, although the group was too small for statistical evaluation.

Granulocytic predominance

Patients with Meg - subtype of Gran-M showed shorter median survival times than those with Gran-M-Meg +, the latter being equal to that of typical CGL (fig $1 b)$ ( $p=$ 0.0001 in both Breslow and Mantel-Cox tests). The latter group also survived for a shorter time than patients with EryGran-M ( $\mathrm{p}=0.02$, Breslow test; and $\mathrm{p}=0.004$, Mantel-Cox test), and than those with GranMeg-M ( $p=0.0001$, Breslow and MantelCox tests). These variant groups did not differ from each other in this respect.

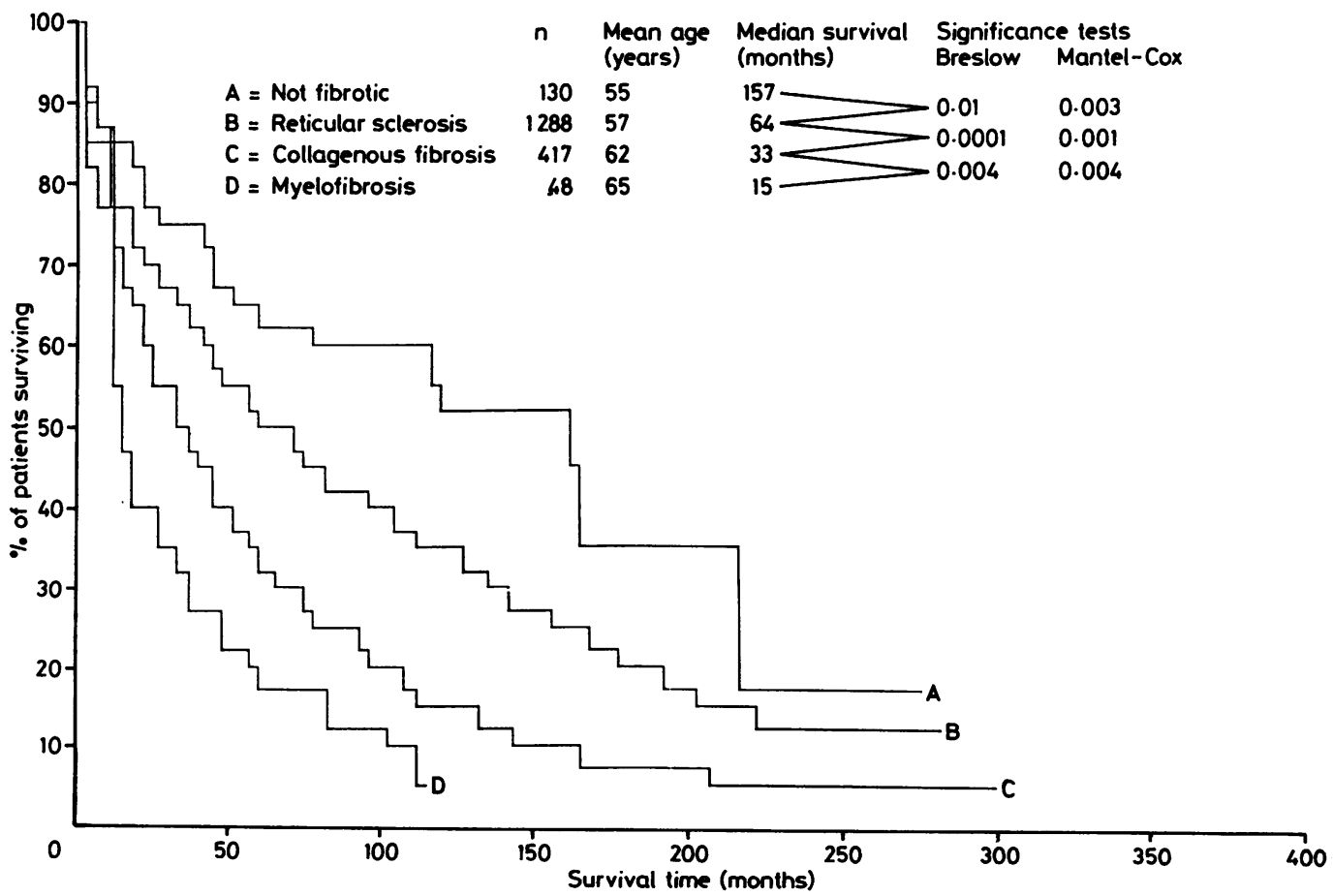




\begin{tabular}{|c|c|c|c|c|c|c|c|c|}
\hline \multirow[b]{3}{*}{ Subtype } & \multicolumn{6}{|c|}{ Degree of fibrosis } & \multirow{2}{*}{\multicolumn{2}{|c|}{$\begin{array}{l}\text { Level of significance for differences } \\
\text { in median survivals }\end{array}$}} \\
\hline & \multicolumn{3}{|c|}{ None or reticular sclerosis } & \multicolumn{3}{|c|}{ Collagenous fibrosis } & & \\
\hline & $n$ & $\begin{array}{l}\text { Mean } \\
\text { age }\end{array}$ & $\begin{array}{l}\text { Median } \\
\text { survival }\end{array}$ & $n$ & $\begin{array}{l}\text { Mean } \\
\text { age }\end{array}$ & $\begin{array}{l}\text { Median } \\
\text { survival }\end{array}$ & $\begin{array}{l}\text { Breslow } \\
\text { p value }\end{array}$ & $\begin{array}{l}\text { Mantel-Cox } \\
\text { pvalue }\end{array}$ \\
\hline $\begin{array}{l}\text { Erythrocytic myellosis (EryGranMeg-M) } \\
\text { Megakaryocytic myelosis (Meg-M-c) } \\
\text { Granulocytic myelosis (Gran-M-Meg +) }\end{array}$ & $\begin{array}{r}340 \\
52 \\
270\end{array}$ & $\begin{array}{l}54 \\
61 \\
53\end{array}$ & $\begin{array}{l}134 \\
\star \\
32\end{array}$ & $\begin{array}{l}18 \\
23 \\
62\end{array}$ & $\begin{array}{l}56 \\
64 \\
63\end{array}$ & $\begin{array}{l}46 \\
82 \\
22\end{array}$ & $\begin{array}{l}0.0001 \\
0.079 \\
0.015\end{array}$ & $\begin{array}{l}0.0009 \\
0.034 \\
0.055\end{array}$ \\
\hline $\begin{array}{l}\text { Erythrocytic megakaryocytis myelosis } \\
\text { (EryMeg-M) } \\
\text { Granulocytic megakaryocytic myelosis }\end{array}$ & 105 & 56 & 130 & 61 & 62 & 71 & 0.01 & 0.0002 \\
\hline $\begin{array}{l}(\text { GranMeg-M-c) } \\
\text { Megakaryocytic immature myelosis }\end{array}$ & 165 & 62 & 74 & 42 & 64 & 39 & 0.03 & 0.01 \\
\hline $\begin{array}{l}(\mathrm{Meg}-\mathrm{M}-\mathrm{i}) \\
\text { Blastic myelosis }\end{array}$ & $\begin{array}{l}52 \\
30\end{array}$ & $\begin{array}{l}55 \\
60\end{array}$ & $\begin{array}{l}20 \\
12\end{array}$ & $\begin{array}{l}57 \\
12\end{array}$ & $\begin{array}{l}55 \\
57\end{array}$ & $\begin{array}{l}8 \\
3\end{array}$ & $\begin{array}{l}0.04 \\
0.04\end{array}$ & $\begin{array}{l}0.01 \\
0.05\end{array}$ \\
\hline
\end{tabular}

75 th quantile: 55 months $=$ more than $50 \%$ of patients alive during control time.

Megakaryocytic predominance

Here the differences in median survival times in the subtypes are most noteworthy, as can be observed from the life table in fig 2: Meg$M$ (fig 1c) $>$ GranMeg-M $>$ Meg-M-i (fig 3a).

\section{Transformation}

The transformed fibrotic and blastic variants are compared in the life table (fig 4), and in figs $3 b-d$. Life expectancy decreased in the following order: OMS > MF > B-M-mult $>$ B-OMS and B-M-un.

\section{CORRELATION BETWEEN FIBROSIS, AGE, AND SURVIVAL}

There were only 130 cases (with a mean age of 55 years) in which no fibrotic changes were evident at all; most ( $n=1289$ with a mean age 57 years) exhibited reticular sclerosis; 468 (mean age 61 years) presented focal to moderate degrees of collagenous fibrosis; osteomyelosclerosis was diagnosed in 198 patients (mean age 60.8 years), and myelofibrosis in 48 patients (mean age 64.8 years). Fibrosis was in general associated with a worse prognosis (fig 5 ).

On the other hand, increasing age diminishes the life expectancy in chronic disorders, and especially in CMPD: 807 of the patients with a mean age of 42 years had a median survival of 74 months, against 55 months for a mean age of 62 years $(n=726) ; p=0.02$ Breslow, $p=0.0007$ Mantel-Cox, and 27 months for mean age of 73 years $(n=688)$. These differences were also significant $(\mathrm{p}=0.0001$, Breslow and Mantel-Cox). There was, however, a pronounced tendency for fibrosis among the subtypes: thus fibrosis was most frequently absent in Meg-M-d; reticular sclerosis was most common in Ery(GranMeg)-M and Gran-M; and collagenous fibrosis was very evident in the clustered subtypes of Meg-M and GranMeg-M and in Meg-M-i.

The significant correlations between the median survival times and fibrotic changes on the one hand, and age on the other, were both positive in most groups (tables 3 and 4). Statistical congruence (using the $\chi^{2}$ test) between age and degree of fibrosis, however, was manifest in only two subtypes-namely, Gran-M-Meg + and EryMeg-M. These variables diverged considerably from one another in Meg-M-i, myelofibrosis and B-Mmult, in which the detrimental influence of fibrosis dominated, and in GranMeg-M-d, in which age, not degree of fibrosis, was the major indicator of poorer life expectancy.

\section{REVISED PROGNOSTIC CLASSIFICATION}

As a result of the above findings, it was necessary to revise our previous scheme of prognostic classification as follows (table 2): 10 groups of CMPD were distinguished primarily by their histology and prognosis and assigned to three classes:

Class I ("typical") was characterised by the uniform connection between the well known histological changes and clinical symptoms with a moderate tendency to transformation.

Class II ("variant") was defined by the less uniform proliferation of more than one cell

\begin{tabular}{|c|c|c|c|c|c|c|c|c|}
\hline \multirow[b]{3}{*}{ Subtype } & \multicolumn{6}{|l|}{ Age } & \multirow{2}{*}{\multicolumn{2}{|c|}{$\begin{array}{l}\text { Level of significance for differences } \\
\text { in median survivals }\end{array}$}} \\
\hline & \multicolumn{3}{|c|}{ Younger patients } & \multicolumn{3}{|c|}{ Older patients } & & \\
\hline & $n$ & $\begin{array}{l}\text { Mean } \\
\text { age }\end{array}$ & $\begin{array}{l}\text { Median } \\
\text { survival }\end{array}$ & $n$ & $\begin{array}{l}\text { Mean } \\
\text { age }\end{array}$ & $\begin{array}{l}\text { Median } \\
\text { survival }\end{array}$ & $\begin{array}{l}\text { Breslow } \\
\text { p value }\end{array}$ & $\begin{array}{l}\text { Mantel-Cox } \\
\text { p value }\end{array}$ \\
\hline $\begin{array}{l}\text { Erythrocytic myelosis (EryGranMeg-M) } \\
\text { Megakaryocytic myelosis (Meg-M-d) } \\
\text { Granulocytic myelosis (Gran-M-Meg +) } \\
\text { Erythrocytic megakaryocytic myelosis }\end{array}$ & $\begin{array}{r}183 \\
73 \\
168\end{array}$ & $\begin{array}{l}46 \\
49 \\
41\end{array}$ & $\begin{array}{l}171 \\
\star \\
35\end{array}$ & $\begin{array}{r}173 \\
73 \\
160\end{array}$ & $\begin{array}{l}66 \\
71 \\
69\end{array}$ & $\begin{array}{l}97 \\
79 \\
23\end{array}$ & $\begin{array}{l}0.0001 \\
0.003 \\
0.0002\end{array}$ & $\begin{array}{l}0.0001 \\
0.0003 \\
0.0003\end{array}$ \\
\hline $\begin{array}{l}\text { (EryMeg-M) } \\
\text { (Erocy }\end{array}$ & 87 & 48 & 136 & 79 & 68 & 66 & 0.0001 & 0.0001 \\
\hline $\begin{array}{l}\text { Granulocytic megakaryocytic myelosis } \\
\text { (GranMeg-M-d) }\end{array}$ & 111 & 52 & 95 & 98 & 73 & 36 & 0.0002 & 0.0001 \\
\hline $\begin{array}{l}\text { Granulocytic megakaryocytic myelosis } \\
\text { (GranMeg-M-c) } \\
\text { Osteomyelosclerosis (OMS) } \\
\text { Myelofibrosis (MF) }\end{array}$ & $\begin{array}{r}123 \\
100 \\
25\end{array}$ & $\begin{array}{l}56 \\
52 \\
57\end{array}$ & $\begin{array}{l}71 \\
42 \\
11\end{array}$ & $\begin{array}{r}104 \\
94 \\
23\end{array}$ & $\begin{array}{l}72 \\
70 \\
74\end{array}$ & $\begin{array}{l}33 \\
22 \\
25\end{array}$ & $\begin{array}{l}0.0001 \\
0.0002 \\
0.32\end{array}$ & $\begin{array}{l}\mathbf{0 . 0 0 0 1} \\
\mathbf{0 . 0 0 0 5} \\
\mathbf{0 . 1 8}\end{array}$ \\
\hline
\end{tabular}

$\star 75$ th quantile: 55 months $=$ more than $50 \%$ of patients alive during control time. 
line with intermediate clinical symptomatology (compared with the "classic" groups), and noticeable instability.

Class III ("transformed") comprised the fully developed fibrotic or blastic variants of I and II, and a small subgroup of possibly "primary" osteomyelosclerosis and myelofibrosis with a (sub)chronic course. The secondary origin and acute to subacute course of the immature and pleomorphic megakaryocytic myeloses resemble the "blastic crises" of other haemopoietic cell lines. As they are generally combined with multilinear haemopoietic proliferation and have a strong tendency to fibrosis, they were integrated into group 9. Collagenous fibrosis in class I varies from $5-19 \%$, in class II from $30-46 \%$, and in class III from $17-100 \%$ of the cases.

\section{Discussion}

The detection of the clonal origin of $\mathrm{CMPD}^{14}$ has contributed to our understanding of its diversity of phenotypes and transformations, which by far exceeds the accepted standards. Moreover, we are beginning to understand some of the consequences of uncontrolled myeloproliferation for the local organisation of cellular production and release, such as the fibrotic sequelae of excess megakaryocytopoiesis. ${ }^{1516}$ It is now also evident that cell line specific symptoms of CMPD have different influences on the time and mode of the final collapse. In the light of these findings the total spectrum of CMPD was analysed primarily from the aspect of the structural pathogenesis at the site of its origin, the bone marrow. This attempt was supported by a 25 year database of technically uniform iliac crest biopsy specimens including case controls, clinical findings, and survival data. Biopsy specimens of previously treated patients were included, because treated and untreated groups did not differ significantly from each other, as has also been found by other authors. ${ }^{12}$

Class I adds a more precise histological scale to the well defined diagnostic criteria of the typical CMPD groups. It becomes clear that isolated proliferation of every haemopoietic cell line has its characteristic prognosis, provided that release of the mature cells into the blood is unimpaired: the most inert form of proliferation is megakaryocytic, followed by erythrocytic, and ultimately granulocytic proliferation as the most unfavourable. Erythrocytic-erythraemic proliferation, however, is rare and its association with polycythaemia vera dubious. In accordance with published findings, ${ }^{1417-22}$ the life expectancy of the trilinear proliferation of polycythaemia vera was found to surpass the rest of CMPD, possibly due to its proximity to healthy bone marrow activity. The consistent longevity of Meg-M contrasts with some previous data ${ }^{3-5}$ which might be due to bias as a result of the inclusion of thrombocythaemic cases belonging to other subgroups. The considerable reported variation in survivals of patients $\mathrm{CGL}^{4523-31}$ could have been caused by the different life expectancies of the GranM-Meg + and -Meg - subgroups, and the previously neglected identification of GranMeg-M, more correctly classified under group 6. This group is also known as "chronic megakaryocytic-granulocytic myelosis (CMGM)", and included considerable numbers of $\mathrm{Ph}^{1}$ positive cases. ${ }^{32}$ Prognostic importance has also been attributed to dysplasia and immaturity of haemopoiesis in CGL. ${ }^{33-35}$ Such cases were excluded from our Gran-M groups. The more malignant course of the eosinophilic variants and their tendency to rapid fibrosis and immature megakaryocytosis have been evaluated previously. ${ }^{10}$

Class II variants are characterised by their comparatively uniform prognosis (by which the class differs significantly from the others), the higher proportions of fibrotic cases, and by the ambivalent cellularity of the blood. Groups 4 and 5 are regarded as variants of polycythaemia vera; group 6 resembles CGL histologically, but may be distinguished clearly from it by megakaryocytosis of the giant and not the dwarf type. Groups 4 and 5 are generally preceded by polycythaemia vera; whereas group 6 may develop de novo or from groups 2 and $3 .^{\circ}$ A further reason for the distinction of the variant groups is their different tendency to blastic or fibrotic transformation. ${ }^{10}$

Class III comprises the transformed variants, understood as the naturally irreversible final stages of the other subgroups. ${ }^{10}$ Myelofibrosis, however, may develop into osteomyelosclerosis; both may acquire blastic dedifferentiation; and blastic forms may become fibrotic. The distinction of myelofibrosis from osteomyelosclerosis, requiring a biopsy specimen of ample size, is important not only in view of the different prognosis, but also in terms of different pathogenesis. Osteomyelosclerosis can no longer be regarded merely as the more advanced stage of myelofibrosis. ${ }^{915}$ It may proceed together with myelofibrosis from the very beginning, or it may never develop during the course of myelofibrosis, or it may take a slower course of its own, possibly triggered by a specific (as yet unknown) osteoblastactivating factor.

Common presages of myelofibrosis and osteomyelosclerosis are the clustered foci of megakaryocytes, observed mostly in groups 1 , 2 , and 6 . These early signs of inefficient megakaryocytopoiesis are followed by the accompanying accumulations of necrotic megakaryocytes and dislocated platelets. Their detrimental effects are most conspicuous when held up against the good prognosis of diffuse megakaryocytosis with safe release of excess platelets. Common presages of unilinear granulocytic blastosis and of immature, pleomorphic, or blastic megakaryocytosis are groups 3 and $5 .^{9}$ Additional studies are required to evaluate the prognosis of the individual cell line forming the B-M-un group. Erythro- and megakaryoblastic crises generally involve more than one cell line and tend to develop into progressive fibrosis; they 
are both classified into group 9 because of similar prognosis and treatment, but are differentiated from unilinear blastic crises (group 10). Primary "acute myelosclerosis"7 is not distinguished by histology from group 9 .

The overall survey of CMPD shows that the course of the disorder depends primarily on the degree of cellular differentiation and the type of the cell lines involved, but much more on the former. Additionally, the involvement of one or more cell lines in itself is a valuable indicator for diagnosis and prognosis. Further prognostic factors are fibrosis and age. The rigid definition of myelofibrosis and osteomyelosclerosis results in shorter survivals for these groups and allows us to analyse the prognostic influence of minor degrees of fibrosis in the other subtypes. ${ }^{41036-}$ ${ }^{40}$ In this way it became evident that reticular sclerosis is not correlated with later osteomyelosclerosis and myelofibrosis, while collagenous fibrosis from its initial focal stages indicates progressive fibrosis. The different prognostic role of fibrosis and age in the subgroups is another argument for the meticulous histological analysis of CMPD. Moreover, it is important to know that this very common procedure has substantial diagnostic and prognostic value of its own.

1 Wasserman LR. A cooperative study of polycythemia vera Ann NY Acad Sci 1985;459:328-33.

2 Gordon MY, Barrett AJ. Chronic myeloid leukaemia and the myeloproliferative disorders. In: Gordon MY, Barrett AJ, eds. Bone marrow disorders. The biological basis of clinical problems. 4th edition. Oxford: Blackwell Scientific Publications, 1985:187-226.

3 Silverstein MN. Primary thrombocythemia. In: Williams WJ, Beutler E, Erslev AJ, Lichtman MA, eds. Hematology (3rd edition). New York: McGraw Hill Book Company, 1983:218-21.

4 Georgii A, Vykoupil KF, Thiele J. Histopathology of bone marrow and clinical findings in chronic myeloproliferative disorders. In: Lennert K, Hübner K, eds. Pathology of the bone marrow. Stuttgart: Gustav Fischer Verlag, 1984 147-69.

5 Bartl R, Burkhardt R, Jäger K, et al. Histologic classification of chronic myeloproliferative disorders (MPD). In: Lennert K, Hübner K, eds. Pathology of the bone marrow. Stuttgart: Gustav Fischer Verlag, 1984:170-3.

6 Ward HP, Block MH. The natural history of agnogenic myeloid metaplasia (AMM) and a critical evaluation of its relationship with the myeloproliferative syndromes. relationship with the myeloprolifer

7 Bearman RM, Pangalis GA, Rappaport H. Acute ("malignant") myelosclerosis. Cancer 1979;43:279-93.

8 Karanas A, Silver RT. Characteristics of the terminal phase of chronic granulocytic leukemia. Blood 1968;32:445-59.

9 Burkhardt R, Bartl R, Jäger K, et al. Working classification of chronic myeloproliferative disorders based on histological, haematological, and clinical findings. J Clin Pathol 1986;39:237-53.

10 Burkhardt R, Bartl R, Jäger $\mathrm{K}$, et al. Chronic myeloproliferative disorders (CMPD). Path Res Pract 1984;179:131-86.

11 Dixon WJ, Brown MB. BMPD-81 biomedical computer programs p-series. System program and statistical development. Berkeley: University of California, 1981.

12 Breslow N. A generalized Kruskal-Wallis test for comparing $k$ samples subject to unequal patterns of censorship. Biometrika 1970;57:579-94.

13 Mantel N. Evaluation of survival data and two new rank order statistics arising in its consideration. Cancer Chemother 1966;50:163-70.

14 Fialkow PJ. Clonal development and stem cell origin of leukemias and related disorders. In: Gunz FW, Henderson ES, eds. Leukemia. New York: Grune and Stratton, 1983:64-74.

15 Burkhardt R, Bartl R, Beil E, et al. Myelofibrosisosteomyelosclerosis syndrome-review of literature and histomorphology. Adv Biosci 1975;16:9-56.

16 Castro-Malaspina H, Moore MAS. Pathophysiological mechanisms operating in the development of myelofibrosis: role of megakaryocytes. Nouv Rev Fr myelofibrosis: role of

17 Lawrence JH. Polycythemia physiology, diagnosis and treatment, based on 303 cases. In: Modern medical mon ographs. New York: Grune and Stratton, 1955:1-136.

18 Calabresi P, Meyer OO. Polycythemia vera: I. Clinical and laboratory manifestations. II. Course and therapy. Ann Int Med 1959;50:1182-216.

19 Perkins J, Israels MCG, Wilkinson JP. Polycythaemia vera: clinical study on a series of 127 patients managed without radiation therapy. $Q J$ Med 1964;33:499-578.

20 Modan B, Lilienfeld AM. Polycythemia vera and leukaemia The role of radiation treatment. Medicine (Baltimore) 1965;44:305-44.

21 Osgood EE. Polycythemia vera: age relationships and survival. Blood 1965;26:243-56.

22 Tubiana $M$, Flamant $R$, Attie E, Hayat M. A study of hematological complications occurring in patients with polycythemia vera treated with ${ }^{32} \mathrm{P}$. Blood 1968;32:536-46.

23 Nathanson IT, Welch CE. Life expectancy and incidence of malignant disease. V. Malignant lymphoma, fibrosarcoma, malignant melanoma, and osteogenic sarcoma. Am coma, malignant melanoma,

24 Shimkin MB, Mettier SR, Bierman HR. Myelocytic leukemia: analysis of incidence, distribution and fatality 1910-1948. Ann Int Med 1951;35:194-212.

25 Best WR, Limarzi LR, Poncher HG. Longevity in leukemia $J$ Lab Clin Med 1951;38:789-94.

26 Tivey $\mathrm{H}$. The prognosis for survival in chronic granulocytic and lymphocytic leukemia. Am J Roentgenol 1954;72: 68-93.

27 Osgood EE. The results of a 15-year-program of treatment of the chronic leukemia with titrated, regularly spaced total-body irradiation with ${ }^{32} \mathrm{P}$ or X-rays. Proceedings International Congress of International Society for International Congress of International

28 Wasserman LR, Gilbert HS. Surgical bleeding in polycythemia vera. Ann NY Acad Sci 1964;115:122-38.

29 Obrecht P. Die Lebenserwartung Hämoblastosekranker In: Deutscher Röntgen kongress 1966, TeilB, Strahlenbehandlung und Strahlenbiologie. München: Urban und Schwarzenberg. 1967:252-64.

30 Paulisch R, Koeppen KM, Anagnou J, Gerhartz H. Uberlebenszeit und Todesursachen der chronischen myeloischen Leukämie. In: Stacher A, Höcker P, eds Erkrankungen der Myelopoese. München: Urban und Schwarzenberg 1976:387-90.

31 Oguma S, Takatsuki K, Uchino $\mathrm{H}$, et al. Factors influencing survival in Philadelphia Chromosome positive chronic myelocytic leukemia. Cancer 1982;50:2928-34.

32 Georgii A, Vykoupil KF, Thiele J. Chronic megakaryocytic granulocytic myelosis-CMGM. A subtype of chronic myeloid leukaemia. Virchows Arch (Pathol Anat) 1980 389:253-68.

33 Sjögren U, Brandt L, Mitelman F. Relation between life expectancy and composition of the bone marrow at diagnosis of chronic myeloid leukemia. Scand J Haematol 1974;12:369-73.

34 Hirschberg T, Berchtold W, Rhyner K, Gmür J. Chronische myeloische Leukämie: multivariate Analyse der initialen Befunde bezüglich Auswirkung auf die mittlere LebensBefunde bezüglich Auswirkung auf die mittlere L

35 Matsuo T, Masao T, Kazutaka K, et al. Prognostic significance of the morphological dysplastic changes in chronic myelogenous leukemia. Leuk Res 1986;3:331-7.

36 Koler RD. Prognosis in the myelofibrosis-myeloid metaplasia syndrome. Clin Res Proc 1957;5:57-69.

37 Pitcock JA, Reinhard EH, Justus BW, Mendelsohn RS. A clinical and pathological study of seventy cases of myelofibrosis. Ann Int Med 1962;57:73-84.

38 Bouroncle BA, Doan CA. Myelofibrosis. Clinical, hematological and pathologic study of 110 patients. $\mathrm{Am} \mathrm{J}$ Med Sci 1962;243:698-715.

39 Silverstein MN, Linman JW. Causes of death in agnogenic myeloid metaplasia. Mayo Clin Proc 1969;44:36-9.

40 Rosenthal DS, Moloney WC. Myeloid metaplasia: A study of 98 cases. Postgrad Med J 1969;45:136-42. 